\title{
LH profile and advancement of ovulation after transcervical infusion of seminal plasma at different stages of oestrus in gilts
}

\author{
D. Waberski ${ }^{1}$, R. Claassen ${ }^{1}$, T. Hahn ${ }^{1}$, P. W. Jungblut ${ }^{2}$, N. Parvizi ${ }^{3}$, \\ E. Kallweit ${ }^{3}$ and K. F. Weitze ${ }^{1}$ \\ IInstitute for Reproductive Medicine, Veterinary School of Hannover, Bünteweg 15, D-30559 Hannover, \\ Germany; ${ }^{2}$ Max-Planck-Institute for Experimental Endocrinology, Feodor-Lynen-Str. 7, D-30625 \\ Hannover, Germany; and ${ }^{3}$ Institute for Animal Husbandry and Behaviour, FAL Mariensee, D-31535 \\ Neustadt a. Rbg., Germany
}

\begin{abstract}
The influence of a transcervical infusion of seminal plasma on preovulatory LH profiles and the advancement of ovulation after seminal plasma infusion for different times during oestrus were investigated using the single uterine horn infusion technique (Mariensee model), in combination with transcutaneous sonographic monitoring of the ovaries. Preparative surgery in 23 German Landrace gilts comprised the detachment of the left uterine horn from the corpus, leaving the caudal end open to the peritoneal cavity but sealing the corpus wound. In six gilts fitted with a permanent jugular vein catheter the patent horns were administered a transcervical infusion of seminal plasma ( $n=5$ cycles) or PBS ( $n=4$ cycles) immediately after the detection of oestrus by a teaser boar. In addition, 17 non-catheterized gilts received infusions of seminal plasma either $\mathrm{O} h(n=3$ gilts), $16 \mathrm{~h}$ ( $n=7$ gilts) or $24 \mathrm{~h}$ ( $n=7$ gilts) after the detection of oestrus. Seminal plasma infusion at the onset of oestrus provoked ovulation in the ipsilateral ovary of the treated horn $8.5 \pm 0.9 \mathrm{~h}$ earlier than in the contralateral (control) ovary. Seminal plasma did not influence the LH profile compared with PBS $(P>0.05)$, but shortened the interval between the $\mathrm{LH}$ peak and ipsilateral ovulation to $23.4 \pm 4.0 \mathrm{~h}$ compared with $31.8 \pm 3.4 \mathrm{~h}$ in the contralateral ovulation $(P \leq 0.01)$. Infusion $16 \mathrm{~h}$ after the onset of oestrus reduced the effect to $4.6 \pm 3.8 \mathrm{~h}$ with a wide range of $0-8 \mathrm{~h}(P<0.01)$. The effect was more pronounced in gilts with long intervals between the onset of oestrus and contralateral ovulation compared with earlier ovulation on the control ovary. Seminal plasma infusion less than $16 \mathrm{~h}$ before contralateral ovulation and $24 \mathrm{~h}$ after the detection of oestrus had no effect. It is concluded that transcervical infusion of seminal plasma early in oestrus synchronizes the variable intervals between the onset of oestrus and ovulation in sows by a locally active mechanism.
\end{abstract}

\section{Introduction}

Induction of ovulation by coitus is a widespread phenomenon in mammalian species. Some species known as spontaneous ovulators, such as cattle, sheep and pigs, may become temporarily induced ovulators for the optimal coordination of the essential steps of fertilization (Jöchle, 1975). Natural mating shortens the interval between the onset of oestrus and ovulation in gilts (Pitkjanen, 1958; Signoret et al., 1972). This has been explained by the stimulatory effect of copulation (Ziecik et al., 1981; Kirsch et al., 1985) and by specific components of boar seminal plasma (Seglin'sh and Brutgans, 1981; Claus, 1989; Weitze et al., 1990). Previous studies that used the single uterine horn infusion technique with the contralateral uterine horn as the untreated control horn (Mariensee model, Jungblut

Received I May 1996. et al., 1991) and sonographic monitoring of ovaries showed that infusion of seminal plasma at the onset of oestrus provoked ovulation in the ipsilateral ovary of the treated horn $10.7 \mathrm{~h}$ earlier than in the contralateral ovary. This provided evidence that a local effect of seminal plasma on the ipsilateral ovary is involved in the advancement of ovulation (Waberski et al., 1995). Recently, it was shown in a sonographic study that the interval between the peak concentration of the $\mathrm{LH}$ surge and ovulation was relatively constant (on average $30 \pm 3 \mathrm{~h}$ ) between sows (Soede et al., 1994). The aim of the present study was to investigate whether a single infusion of seminal plasma into the uterine horn influences peripheral concentrations of plasma LH in relation to the time of ovulation on ipsi- and contralateral ovaries. In addition, the influence of the time of infusion at different stages of oestrus on the advancement of ovulation by seminal plasma was investigated. 


\section{Materials and Methods}

\section{Animals and surgery}

23 German Landrace gilts with an average body mass of $95 \mathrm{~kg}$ were surgically prepared according the Mariensee model (Jungblut et al., 1991), as described in detail by Waberski et al. (1995). Surgery was carried out under general anaesthesia using Stresnil $^{(\mathbb{R})}$ (Janssen $\mathrm{GmbH}$, Neuss) and Nembutal ${ }^{\mathbb{R}}$ (WDT, Hannover). Briefly, the left uterine horn was detached from the corpus, leaving the caudal end open to the peritoneal cavity but sealing the corpus wound. For easier sonographic distinction, the mesovarium of the left ovary was loosely attached to the abdominal wall using a synthetic yarn (Synthofil ${ }^{\mathrm{R}}$ : Braun, Melsungen). Animals were allowed to recover from surgery in individual pens for 10 days and were then transported to the Hannover Veterinary School. They were housed in groups of two or four with olfactory and visual contact with the boar. Ten days after ovulation in the first oestrus after transport, six gilts were fitted with permanent jugular vein catheters under general anaesthesia. Catheterized pigs were housed in individual pens to prevent perturbation of the catheters by other gilts.

\section{Collection of blood samples}

Catheterized animals were used to handling and to the blood sampling procedure before the experimental period began. Blood samples were collected into tubes containing EDTA (Monovettes ${ }^{\mathrm{B}}$, Sarstedt) from day 10 to day 17 after ovulation in the first oestrus, twice daily, at 08:00 and 20:00 h. Thereafter, the frequency of collection of blood samples was increased to intervals of $60 \mathrm{~min}$ until $24 \mathrm{~h}$ after the onset of oestrus. Thereafter, blood samples were collected at intervals of $4 \mathrm{~h}$ until ovulation on the contralateral ovary. Immediately after collection, blood samples were centrifuged at $2500 \mathrm{~g}$ for $15 \mathrm{~min}$ and the plasma was stored at $-20^{\circ} \mathrm{C}$ until hormone analysis.

\section{Hormone measurements}

Luteinizing hormone was determined in duplicate in $100 \mu \mathrm{l}$ plasma by a homologous radioimmunoassay as described by Pomerantz et al. (1974) and Ponzilius et al. (1986). The specific antiserum (UCB porcine-Anti LH, UCB, Brussels) was raised in rabbits against porcine $\mathrm{LH}$. The lower limit of detection was $0.2 \mathrm{ng} \mathrm{LH} \mathrm{ml}{ }^{-1}$ plasma. Porcine LH, $1 \mathrm{mg}$, used for labelling and standards had a biological activity equivalent to $0.9 \mathrm{mg}$ $\mathrm{NIH}$ standard LH-S19. Intra- and interassay coefficients of variation were $3.5 \%$ and $6 \%$, respectively.

\section{Seminal plasma}

Semen was collected from 50 adult boars at the Artificial Insemination Center Neustadt a.d. Aisch over a period of 2 months. Samples were centrifuged at $3000 \mathrm{~g}$ for $20 \mathrm{~min}$ and the cell-free plasma was stored frozen at $-20^{\circ} \mathrm{C}$. The plasma pool was prepared by thawing the frozen samples and mixing them when fully thawed. Aliquots of $100 \mathrm{ml}$ were stored at $-20^{\circ} \mathrm{C}$ until use.

\section{Transcervical infusions}

In catheterized animals transcervical infusions of $100 \mathrm{ml}$ seminal plasma or PBS into the patent uterine horns were performed by insemination catheters as soon as tolerance to mounting by the boar was detected. In three gilts the jugular vein cannula remained patent for two consecutive cycles. These gilts received transcervical infusions of seminal plasma in their second oestrus after transport followed by infusions of PBS in the third oestrus. Of the remaining catheterized gilts, two were infused with seminal plasma and one with PBS in the second oestrus after transport. In the non-catheterized animals transcervical seminal plasma infusions were performed at three different times: in three gilts immediately after detection of tolerance to the boar, in seven gilts $16 \mathrm{~h}$, and in seven gilts $24 \mathrm{~h}$ thereafter. All non-catheterized gilts were treated in their second or third oestrus after transport. Refluxes of infused solutions were collected for 5 min after the completion of the infusion and the volumes were measured.

\section{Assessment of the intervals between the onset of oestrus and ovulation}

Oestrus was checked three times a day by introducing the gilts into the pen of a teaser boar (08:00, 16:00, 24:00 h). The onset of oestrus was defined as half of the time interval between the last rejection of mounting and the first tolerance. During oestrus, the ovaries were examined sonographically every $4 \mathrm{~h}(04: 00,08: 00,12: 00,16: 00,20: 00,24: 00 \mathrm{~h})$ to determine the time of ovulation. Transcutaneous sonography was performed using a $5 \mathrm{MHz}$ sector scanner (Sonoline SI-250, Siemens, Erlangen), as described by Weitze et al. (1989). The time of ovulation was set at $t / 2$ between the last detection of follicles and their subsequent disappearance. Detection of fewer follicles than in the preceding scan followed by a total disappearance in the subsequent examination was taken as sign of ongoing ovulation. In this case, the time at which a reduction in number of follicles was registered was taken as the time of ovulation. The effect of an infused solution on the advancement of ovulation in a gilt was calculated from the time difference between ovulation in the ipsilateral (treated horn) and contralateral (control horn) ovaries.

\section{Statistical analyses}

Statistical analyses were made using the GLM procedure from SAS (SAS/STAT, 1989). In gilts with a positive response to seminal plasma infusion, the interval from the onset of oestrus to contralateral ovulation was found to have a significant $(P \leq 0.01)$ influence on the time differences between ipsi- and contralateral ovulations and was therefore considered as a covariate. The volume of reflux $(0-52 \mathrm{ml})$ and the duration of oestrus $(48-72 \mathrm{~h})$ did not have a significant $(P>0.05)$ influence on the time difference between ipsi- and contralateral ovulations and were therefore not considered as covariates. The onset and the end of the preovulatory LH surge were determined as the first and the last sample in which the $\mathrm{LH}$ concentration was higher than the mean basal LH concentration plus one SD. The basal $\mathrm{LH}$ concentration was the mean LH concentration in blood samples collected between day 10 
Table 1. Characteristics of oestrus, LH surge, ipsilateral (patent uterine horn) and contralateral (detached uterine horn) ovulation after infusion of seminal plasma ( $n=5$ cycles) or PBS ( $n=4$ cycles) into a patent uterine horn of gilts

\begin{tabular}{|c|c|c|c|c|c|c|}
\hline \multirow[b]{2}{*}{ Parameter } & \multicolumn{3}{|c|}{ Seminal plasma } & \multicolumn{3}{|c|}{ PBS } \\
\hline & \multicolumn{2}{|c|}{ Mean $\pm \mathrm{sl}$} & Range & \multicolumn{2}{|c|}{ Mean $\pm S D$} & Range \\
\hline \multicolumn{7}{|l|}{ Oestrus and ovulation } \\
\hline Oestrus duration $(\mathrm{h})$ & $60.8 \pm$ & 4.4 & $56-64$ & $58.0 \pm$ & 4.0 & $56-64$ \\
\hline Interval from onset of oestrus to ipsilateral ovulation $(\mathrm{h})$ & $33.6 \pm$ & $0.9^{\mathrm{ax}}$ & $32-34$ & $44.5 \pm$ & $6.0^{\mathrm{b}}$ & $36-50$ \\
\hline Interval from onset of oestrus to contralateral ovulation (h) & $42.0 \pm$ & $0^{y}$ & $42-42$ & $44.5 \pm$ & 6.0 & $36-50$ \\
\hline Difference between ipsi- and contralateral ovulation (h) & $8.4 \pm$ & $0.9^{\mathrm{a}}$ & $8-10$ & $0 \pm$ & $0^{b}$ & $0-0$ \\
\hline \multicolumn{7}{|l|}{ LH characteristics } \\
\hline Basal concentrations $\left(\mathrm{ng} \mathrm{ml} \mathrm{ml}^{-1}\right)$ & $0.6 \pm$ & 0.2 & $0.3-0.7$ & $0.7 \pm$ & 0.3 & $0.4-1.1$ \\
\hline Maximum concentration $\left(\mathrm{ng} \mathrm{ml}^{-1}\right)$ & $6.6 \pm$ & 1.5 & $4.5-8.4$ & $7.6 \pm$ & 1.8 & $5.3-9.4$ \\
\hline Rise in concentration from basal to maximum (\%) & $1334 \pm 4$ & & $900-2000$ & $1133 \pm 3$ & 19 & $806-1516$ \\
\hline Time from onset of LH surge to LH-maximum (h) & $12.6 \pm$ & 6.3 & $6-22$ & $10.8 \pm$ & 3.5 & $7-15$ \\
\hline Duration of the LH surge $(h)$ & $35.2 \pm$ & 9.4 & $23-47$ & $34.3 \pm$ & 16.9 & $22-59$ \\
\hline \multicolumn{7}{|l|}{ Timing of L.H surge relative to oestrus and ovulation } \\
\hline Interval from onset of oestrus to onset of LH surge (h) & $-2.8 \pm$ & 6.7 & $-12-5$ & $2.8 \pm$ & 4.6 & $-2-9$ \\
\hline Interval from onset of oestrus to peak LH concentration (h) & $10.2 \pm$ & 3.4 & $5-14$ & $13.5 \pm$ & 6.8 & $5-21$ \\
\hline Interval from onset of LH surge to ipsilateral ovulation (h) & $34.0 \pm$ & $6.0^{x}$ & $29-44$ & $41.8 \pm$ & 3.0 & $38-45$ \\
\hline Interval from onset of LH surge to contralateral ovulation (h) & $44.4 \pm$ & $6.0^{y}$ & $37-52$ & $41.8 \pm$ & 3.0 & $38-45$ \\
\hline Interval from peak LH concentration to ipsilateral ovulation (h) & $23.4 \pm$ & $4.0^{\mathrm{ax}}$ & $18-29$ & $31.0 \pm$ & $2.2^{\mathrm{b}}$ & $29-34$ \\
\hline Interval from peak $\mathrm{LH}$ concentration to contralateral ovulation (h) & $31.8 \pm$ & $3.4^{y}$ & $28-37$ & $31.0 \pm$ & 2.2 & $29-34$ \\
\hline
\end{tabular}

Results are from nine cycles of six gilts. Three gilts received infusions of seminal plasma and PBS in two consecutive cycles.

a,b Values within rows with different superscripts are significantly different $(P \leq 0.01)$.

${ }^{x}, y$ Values within columns with different superscripts are significantly different $(P \leq 0.01)$.

and day 17 of the oestrous cycle. The relative rise in LH per gilt was calculated by dividing the concentration by basal LH concentration and multiplying the result by 100 . The comparison of adjusted means was made using the Student's $t$ test.

The relationship between the intervals from infusion to contralateral ovulation and the time difference between ipsiand contralateral ovulation was described by the non-linear regression model $y=\mathrm{C} 1 \cdot \arctan (\mathrm{C} 3(x-\mathrm{C} 4))+\mathrm{C} 2$. The coefficients $\mathrm{C} 1$ and $\mathrm{C} 2$ were first estimated by the arctan function. The coefficients $\mathrm{C} 3$ and $\mathrm{C} 4$ were calculated using the non-linear procedure of SAS. The coefficients $\mathrm{C} 1$ and $\mathrm{C} 2$ were then corrected using the linear regression procedure of SAS. The resulting model was $y=3.47 \cdot \arctan (0.2(x-22.2))+4.08$. The confidence interval for the coefficient $\mathrm{C} 3$ was between 0.05 and 0.35 . The confidence interval for the coefficient $\mathrm{C} 4$ was between 19.06 and 25.35 .

\section{Results}

Effect of seminal plasma infusions at the onset of oestrus on $L H$ profile and ovulation

In gilts infused with seminal plasma at the onset of oestrus, the intervals between the beginning of oestrus and ovulation were $8.4 \mathrm{~h}(8-10 \mathrm{~h})$ shorter $(P \leq 0.01)$ in the ipsilateral than in the contralateral (control) ovaries (Table 1). Infusion of PBS had no effect on ovulation in the ipsilateral ovary. LH concentrations and the duration of the $\mathrm{LH}$ surge, the interval from the onset of oestrus to the onset and peak of LH surge, and the interval from the onset and peak of LH surge to ovulation in the contralateral ovary were not significantly different $(P>0.05)$ between the groups treated with seminal plasma and those treated with PBS. Seminal plasma shortened the interval from the onset of $\mathrm{LH}$ surge to ovulation in the ipsilateral ovary to $34.0 \mathrm{~h}(29-44 \mathrm{~h})$ compared with $44.4 \mathrm{~h}$ $(37-52 \mathrm{~h})$ in the contralateral ovary $(P \leq 0.01)$. In the group treated with seminal plasma, the interval from the LH peak to ipsilateral ovulation was reduced to $23.4 \mathrm{~h}(18-29 \mathrm{~h})$ compared with $31.8 \mathrm{~h}(28-37 \mathrm{~h})$ in the contralateral ovary $(P \leq 0.01)$. Three gilts received infusions of seminal plasma and PBS in two consecutive cycles. In these gilts both the $\mathrm{LH}$ profile and the time of ovulation corresponded to the results obtained for all gilts: the maximum concentration of $\mathrm{LH}$ and the duration of the LH surge in the seminal plasma cycles were $7.0 \pm 1.3 \mathrm{ng} \mathrm{ml}^{-1}$ and $35.3 \pm 5.9 \mathrm{~h}$, and in the PBS cycles $8.4 \pm 1.8 \mathrm{ng} \mathrm{ml}^{-1}$ and $32.0 \pm 7.2 \mathrm{~h}$, respectively. In the same three gilts the intervals from the onset of LH surge and the peak $\mathrm{LH}$ concentration to ipsilateral ovulation in the seminal plasma cycles were $36.7 \pm 6.4 \mathrm{~h}$ and $21.7 \pm 3.5 \mathrm{~h}$, and in the PBS cycles $40.7 \pm 2.5 \mathrm{~h}$ and $31.3 \pm 2.5 \mathrm{~h}$, respectively. All six catheterized gilts showed synchronous ovulation on both ovaries after infusion of PBS and advanced ovulations on ipsilateral ovaries after infusion of seminal plasma. There was no difference between the intervals from onsets and peaks of LH surges and contralateral ovulations between the groups $(P>0.05)$. The time of infusion relative to the onset of the LH surge and day of oestrous cycle is shown for individual gilts in the seminal plasma group (Fig. 1). Gilts entered oestrus between day 18 and 20 after the previous ovulation. All infusions in both seminal plasma and PBS groups were performed at the onset or during the LH surge. 


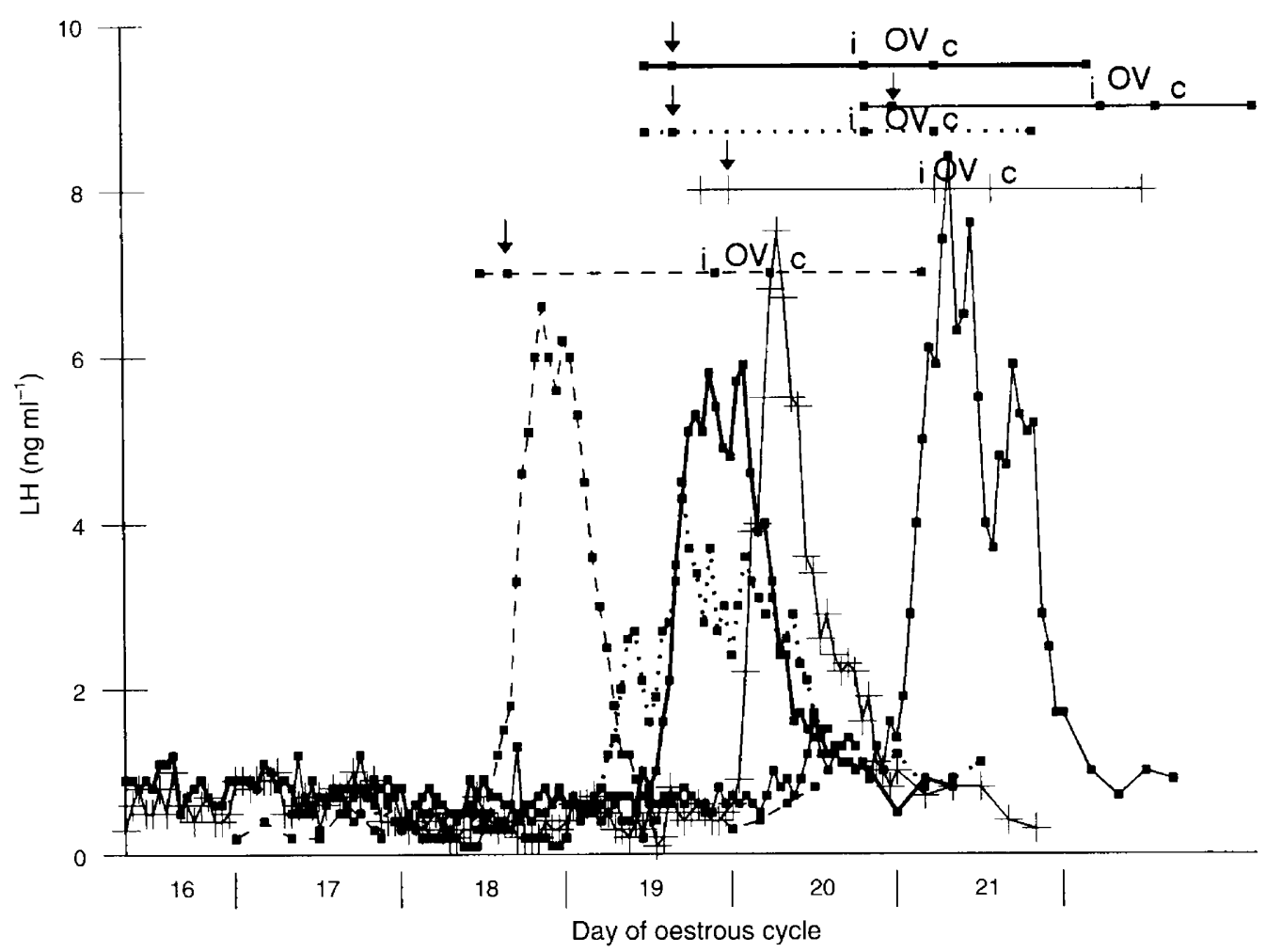

Fig. 1. LH surges relative to oestrus duration (horizontal lines), time of seminal plasma infusions into single-uterine horns (arrows) and ipsi-(i) and contralateral (c) ovulations (OV; marked in horizontal lines), $(n=5$ gilts).

Table 2. The advancement of ipsilateral ovulation compared with contralateral ovulation after single uterine horn infusion of seminal plasma at different times in oestrus in gilts

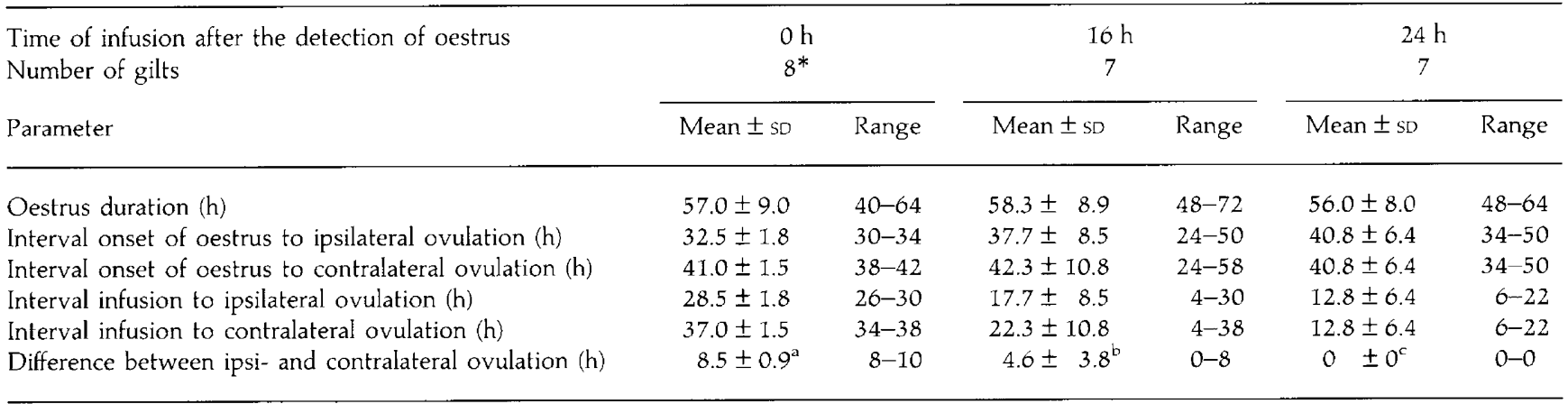

*Five gilts with permanent jugular vein catheters are included.

a-c Values with different superscripts are significantly different $(P<0.01)$.

Effect of the time of seminal plasma infusion on the time between the onsets of oestrus and ovulation

Infusions at $24 \mathrm{~h}$ after the detection of oestrus did not result in earlier ipsilateral ovulation (Table 2). Infusions of seminal plasma at $16 \mathrm{~h}$ after the detection of oestrus reduced $(P<0.01)$ the time difference between ipsi- and contralateral ovulation to an average of $4.6 \mathrm{~h}$ with a range of $0-8 \mathrm{~h}$, compared with the infusion immediately after the detection of oestrus $(8.5 \mathrm{~h})$. The two gilts in this group that showed no difference between ipsiand contralateral ovulation had short intervals from the onset of oestrus to ovulation ( 24 and $34 \mathrm{~h}$, respectively). Infusions at less than $22 \mathrm{~h}$ before ovulation failed to advance ovulation on ipsilateral ovaries (Fig. 2). Infusions at times longer than $32 \mathrm{~h}$ before ovulation led to an advancement of ovulation of at least $8 \mathrm{~h}(8-10 \mathrm{~h})$. Infusions at times in between showed a variable effect from $2 \mathrm{~h}$ to $8 \mathrm{~h}$.

\section{Discussion}

In accordance with earlier observations using the single uterine horn infusion technique in combination with sonographic 


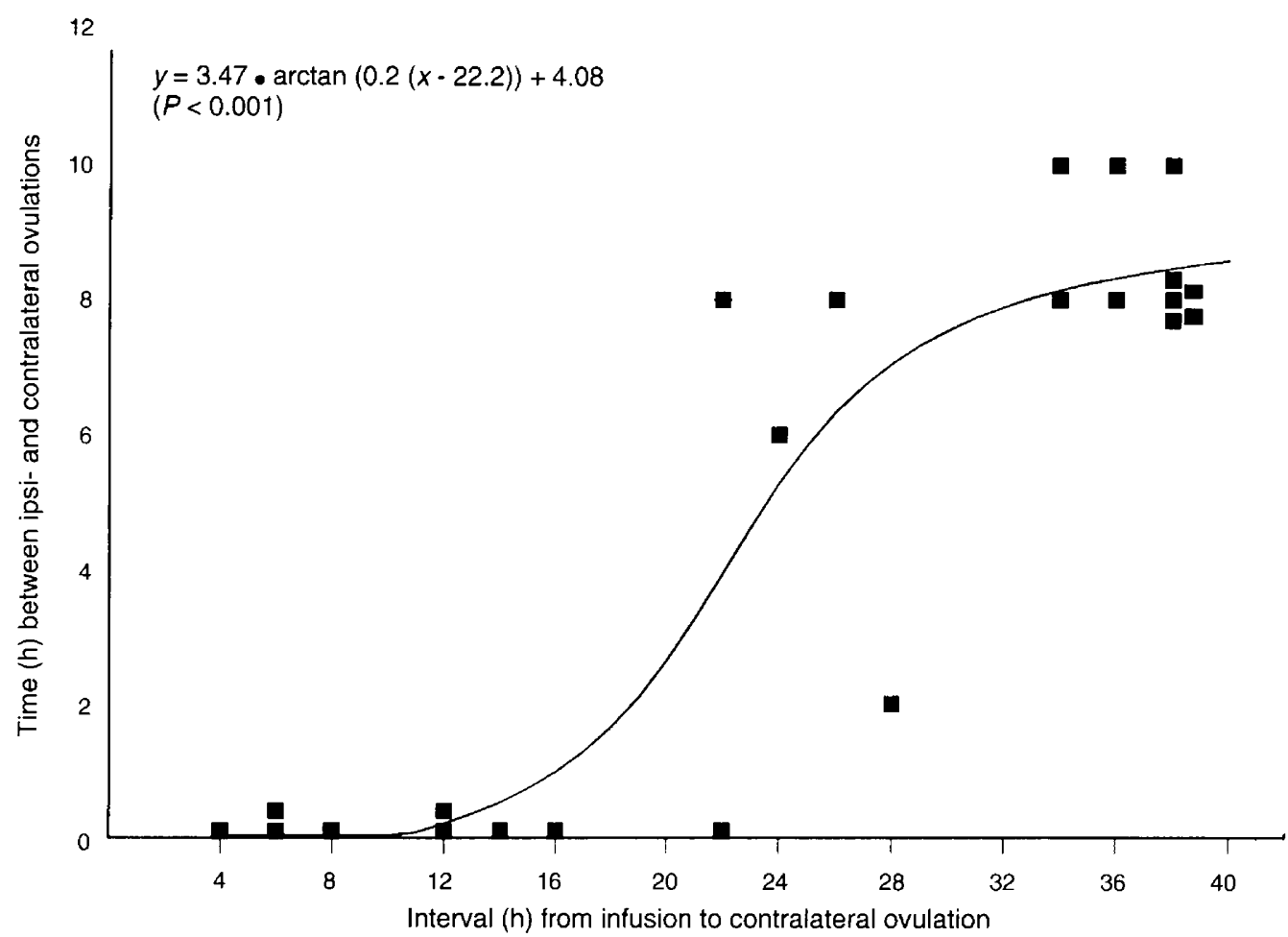

Fig. 2. Relationship between the intervals from seminal plasma infusion to control (contralateral) ovulations and the time differences between ipsi- and contralateral ovulations ( $n=22$ gilts).

detection of ovulation (Waberski et al., 1995), the present study has shown that seminal plasma advances ovulation in the ipsilateral ovary of the treated horn by 8 to $10 \mathrm{~h}$ in comparison with the contralateral (control) ovary. Since the amount of active seminal plasma components such as oestrogens varies widely between boars and season (Claus et al., 1983), a pool of seminal plasma was used to exclude ejaculate specific influences. The Mariensee model used in both studies requires few animals and allows for the distinction between local and systemic effects, since the times of ovulation are compared between ovaries at the treated and the untreated side in each gilt. In 23 cycles of 13 gilts of a previous study (Waberski et al., 1995) and in 11 cycles of 11 gilts in the present study, the single uterine horn infusion of ineffective media or of seminal plasma at a late oestrous stage was followed by synchronous ovulation on both ovaries at regular intervals after the onset of oestrus. Gilts in which an infused medium was found to be ineffective showed ipsilaterally advanced ovulation after the infusion of seminal plasma or an active component thereof. The loose attachment of the left mesovarium at the abdominal wall for better sonographic distinction of left and right ovaries, therefore, did not influence the time of ovulation. Here, we confirmed our previous conclusion that the ovulation advancing effect of seminal plasma is based on local phenomena, since $\mathrm{LH}$ concentrations and LH surge profiles were not influenced by the infusion of seminal plasma compared with PBS infusion. This is in accordance with the report of Ziecik et al. (1981) who found no difference in the LH profiles of inseminated compared with non-inseminated gilts. However, Kirsch et al. (1985) suggested an earlier rise of preovulatory LH surge in both mated and inseminated gilts compared with control animals, and Claus (1989) suggests that oestrogens in seminal plasma may trigger a preovulatory LH surge. The present study cannot rule out influences of the insemination procedure and of the distension reflex on LH release. However, a specific effect of seminal plasma on LH profile was not seen. This finding suggests that the proposed enhancement of LH release by seminal plasma with subsequent ovulation in camels ( $\mathrm{Xu}$ et al., 1985; Pan et al., 1992) is governed by a different mechanism.

In the study reported here, the interval from the LH peak to ovulation in the ovary adjacent to the untreated uterine horn was in accordance with recent observations using transrectal sonography for the detection of ovulation in sows (Soede et al., 1994; Mburu et al., 1995). LH profiles may not differ between gilts and sows (Tilton et al., 1982; Blair et al., 1994). The model used in this study clearly established that seminal plasma shortens the interval between the LH peak and ipsilateral ovulation to $23.4 \mathrm{~h}$, on average, compared with $\mathrm{LH}$ peak ovulation intervals of $31.8 \mathrm{~h}$ in the contralateral ovary. The minimal interval between LH peak and ovulation was $18 \mathrm{~h}$, which is considerably longer than the minimal interval of $8 \mathrm{~h}$ in untreated multiparous sows, as described in the sonographic study of Dalin et al. (1995).

The timing of the preovulatory peak of $\mathrm{LH}$ varies in pigs from $32 \mathrm{~h}$ before to $22 \mathrm{~h}$ after the onset of oestrus (Helmond et al., 1986). In the present study, LH peaks were found between 5 and $21 \mathrm{~h}$ after the onset of oestrus. This more synchronized pattern can be explained by the exposure of the gilts to the boar (Claus, 1989). Therefore, all catheterized gilts were infused at the onset of or during the LH surge. The infusion of seminal plasma at $16 \mathrm{~h}$ after the detection of oestrus failed to advance ipsilateral ovulation when the time interval 
between infusion and ovulation was greater than $16 \mathrm{~h}$. In addition, seminal plasma administered $24 \mathrm{~h}$ after the detection of oestrus, at the time when first insemination is usually performed, also had no effect on the time of ovulation. However, the effects of seminal plasma on fertilization other than those promoting ovulation may be effective at this time (Waberski et al., 1996). As reported by Waberski et al. (1995), the ovulation advancing effect of seminal plasma infused at the onset of oestrus was more pronounced in gilts exhibiting long intervals between the onset of oestrus and ovulation in the control ovary, than those with shorter intervals. It is concluded that natural mating early in oestrus is a useful physiological mechanism for synchronizing the widely varying intervals between the onset of oestrus and ovulation in sow herds as described by Weitze et al. (1994) and that the seminal plasma is instrumental in this process. Since the success of fertilization is strongly related to short intervals between insemination and ovulation (Waberski et al., 1994; Soede et al., 1995), seminal plasma infusions early in oestrus are likely to enhance fertilization chances by advancing ovulation. The mechanism by which a yet unknown peptide component together with oestrogens in boar seminal plasma (Waberski et al., 1995) shortens the $\mathrm{LH}$ surge-ovulation interval and the consequences for the oocyte maturation stage, however, remain to be elucidated.

This study was supported by the Association of German Pig Producers (ZDS, Bonn) and the Dr. Dr. h.c. Karl Eibl Foundation (Neustadt a.d. Aisch). The authors thank Professor Waldmann and G. Borchardt for their help and the AI Center Neustadt a.d. Aisch e.V. for providing the seminal plasma.

\section{References}

Blair RM, Coughlin CM, Minton JE and Davis DL (1994) Peri-oestrus hormone profiles, embryonic survival and variation in embryonic development in gilts and primiparous sows Journal of Reproduction and Fertility 101 167-173

Claus R (1989) Oestrogens of the boar: effects on male and female reproductive functions. In Reproductive Biology and Medicine pp 136-147 Eds AF Holstein, KD Voigt and D Grässlin. Diesbach Verlag, Berlin

Claus R, Schopper D and Wagner HG (1983) Seasonal effects on steroids in blood plasma and seminal plasma of boars Journal of Steroid Biochemistry 19 $725-729$

Dalin AM, Nanda T, Hultén F and Einarsson S (1995) Ovarian activity at naturally attained oestrus in the sow. An ultrasonographic and LH study Acta Veterinaria Scandinavica 36 377-382

Helmond F, Aarnik A and Oudenaarden C (1986) Periovulatory hormone profiles in relation to embryonic development and mortality in pigs. In Embryonic Mortality in Farm Animals pp 119-125 Eds JM Sreenan and MG Diskin. Martinus Nijhoff Publishers, Dordrecht

Jöchle $W$ (1975) Current research in coitus-induced ovulation: a review Journal of Reproduction and Fertility Supplement 22 165-207

Jungblut PW, Sierralta WD, Henning M and Kallweit E (1991) Die transzervikale Injektion in das Uteruslumen von kastrierten Schweinen als zell- und organbiologische Versuchsanordnung. Das Mariensee Modell Journal of Experimental Animal Science $34229-235$
Kirsch JD, Tilton JE, Ziecik A, Weigl R, Schaffer T and Williams GL (1985) Effects of various mating stimuli on pituitary release of luteinizing hormone in the gilt Domestic Animal Endocrinology 2 99-104

Mburu JN, Einarsson S, Dalin A-M and Rodriguez-Martinez H (1995) Ovulation as determined by transrectal ultrasonography in multiparous sows: relationships with oestrous symptoms and hormonal profiles Joumal of Veterinary Medicine A 42 285-292

Pan G-W, Zhao X-X, Chen B-H, Jiang S, Huang Y-M, Zu Y-S and Wang H-Y (1992) The ovulation-inducing effect of seminal plasma in the Bactrian camel. In Proceedings of the First International Camel Conference pp 159-161 Eds WR Allen, AJ Higgins, IG Mayhew and DH Snow. JF Wade, R\&W Publications (Newmarket) Ltd, Dubai

Pitkjanen IG (1958) The time of ovulation in sows Svinovodstvo 12 38-40

Pomerantz DK, Ellendorff F, Elsaesser F, König A and Smidt D (1974) Plasma LH changes in intact adult, castrated adult and pubertal male pigs following various doses of synthetic luteinizing hormone-releasing hormone (LH-RH) Endocrinology 94 330-335

Ponzilius KH, Parvizi N, Elsaesser F and Ellendorff F (1986) Ontogeny of secretory patterns of $\mathrm{LH}$ release and effects of gonadectomy in the chronically catheterized pig fetus and neonate Biology of Reproduction $\mathbf{3 4}$ 602-612

SASISTAT (1989) User's Guide SAS Institute Inc, Cary, NC

Seglin'sh A and Brutgans YA (1981) The effect of boar seminal plasma, oxytocin and carbachol on conception Pig News and Information 2 197-198

Signoret JP, Du Mesnil du Buisson D and Mauléon P (1972) Effect of mating on the onset and duration of ovulation in the sow Journal of Reproduction and Fertility 31 327-330

Soede NM, Helmond FA and Kemp B (1994) Periovulatory profiles of oestradiol, $\mathrm{LH}$ and progesterone in relation to oestrus and embryo mortality in multiparous sows using transrectal ultrasonography to detect ovulation Journal of Reproduction and Fertility 101 633-641

Soede NM, Wetzels CCH, Zondag W, de Koning MAI and Kemp B (1995) Effects of time of insemination relative to ovulation, as determined by ultrasonography, on fertilization rate and accessory sperm count in sows Journal of Reproduction and Fertility 104 99-106

Tilton JE, Foxcroft GR, Ziecik AJ, Coombs SL and Williams GL (1982) Time of the preovulatory LH surge in the gilt and sow relative to the onset of behavioral estrus Theriogenology 18 227-236

Waberski D, Weitze KF, Gleumes T, Schwarz M, Willmen T and Petzoldt R (1994) Effect of time of insemination relative to ovulation on fertility with liquid and frozen boar semen Theriogenology 42 831-840

Waberski D, Sudhoff H, Hahn T, Jungblut PW, Kallweit E, Calvete JJ, Ensslin M, Hoppen H-O, Wintergalen N, Weitze KF and Töpfer-Petersen E (1995) Advanced ovulation in gilts by the intrauterine application of a low molecular mass pronase-sensitive fraction of boar seminal plasma Journal of Reproduction and Fertility 105 247-252

Waberski D, Soares JAG, Bandeira de Arruda E and Weitze KF (1996) Effect of a transcervical infusion of seminal plasma prior to insemination on the fertilizing competence of low numbers of boar spermatozoa at controlled AI-ovulation intervals Animal Reproduction Science 44 165-173

Weitze KF, Habeck O, Willmen T and Rath D (1989) Detection of ovulation in the sow using transcutaneous sonography Zuchthygiene 24 40-42

Weitze KF, Lotz JH, Everwand A, Willmen T and Waberski D (1990) Interaction between inseminate, uterine and ovarian function in the sow. II. Investigations into the influencing of ovulation by the use of sperm-free media Reproduction Domestic Animals 25 197-204

Weitze KF, Wagner-Rietschel H, Waberski D, Richter L and Krieter J (1994) The onset of heat after weaning, heat duration, and ovulation as major factors in Al timing in sows Reproduction in Domestic Animals 29 433-443

Xu YS, Wang HY, Zeng GQ, Jiang GT and Gao YH (1985) Hormone concentrations before and after semen-induced ovulation in the bactrian camel (Camelus bactrianus) journal of Reproduction and Fertility 74 341-346

Ziecik A, Tilton JE and Williams GL (1981) Effect of mating on the luteinizing hormone surge in the pig Journal of Animal Science 53 434-438 